PROF-887

\title{
POLYCYSTIC KIDNEY DISEASE
}

\author{
DR. MUHAMMAD AKRAM MALIK, \\ FCPS (Surgery), FCPS (Urology) \\ Senior Registrar \\ Department of Urology \\ Allied Hospital Faisalabad. \\ DR. MUNIR AHMED, PGR \\ Department of Urology \\ Allied Hospital Faisalabad.
}

\author{
DR. ZAHID IQBAL \\ MS(Urology), DU (Austria) \\ Professor of Urology \\ Allied Hospital Faisalabad.
}

ABSTRACT...Objectives: (1) To document various clinical presentation of disease. (2) To assess family members. (3) To audit our experience of management of this disease. Study Design: Prospective study. Period: 01-01-2001 to 31-12-2004. Material \& Methods: All patients presented with ADPKD were included in the study. Detailed history, clinical examination was performed in each case. Pain was managed by NSAIDS and USG was done in each case. Urinary tract infection was treated with antibiotics according to culture sensitivity. Blood pressure was managed by ACE inhibitors. Stones were treated with URS, \pm DJ stents and ESWL. Patients with ESRD were offered renal replacement therapy in the form of haemodialysis and renal transplant. Results: Total number of patients was 19. Male 10 and 9 Female. Age ranges from 32-65 years. Pain abdomen and flank was main presenting complaint in $95 \%$ patients. Fever \& renal stones were present in $10(53 \%)$ and $08(42 \%)$ of patients respectively. Extra renal manifestations were present in $02(11 \%)$ of patients. 06 patients progressed to ESRD. 03 patients died due to ESRD. Parents of 04 patients had ADPKD. Majority 10(52\%) could not be evaluated. 06 Patients (21\%) had their sisters and brothers involved with ADPKD. DJ Stenting and ESWL was the only surgical management done. Conclusion: ADPKD is hereditary disorder. No cure is possible. Management of this disease by medication and surgery only slows the progress of renal failure. Counseling should be done to avoid cousin marriage in affected families. Chromosome analysis facilities should be available to affected families free of cost for early detection of disease.

Key words: $\quad$ ADPKD, PKD, Renal cysts, ESRD, Renal transplant.

\section{INTRODUCTION}

Autosomal dominant ploy-cystic kidney disease (ADPKD) is one of the most common inherited disorders in the $\operatorname{man}^{1,2}$. It is the most frequent genetic cause of renal 
failure in adults, accounting for $10 \%$ of patients on dialysis in United States ${ }^{3,4}$. ADPKD is a multi systemic and generally a progressive disorder characterized by formation and generally a enlargement of renal cysts in the kidney and other organs, liver, spleen and pancreas etc ${ }^{5}$. Due to autosomal inheritance, each off spring has $50 \%$ chance of inheriting the disorder ${ }^{6,7}$. ADPKD is a genetically heterogeneous condition with at least 3 genes involved as follows ${ }^{8,9}$.

- $\quad$ PKD1 is located on 16 p 13.3 and accounts for majority $(85 \%)$ of cases.

- $\quad$ PKD2 is located on 4 q 22 and accounts for $15 \%$ of ADPKD cases.

- $\quad$ PKD3 is rare and yet not mapped.

The main features of ADPKD is bilateral progressive cystic dilatation of renal tubules. Hepatic cysts, pancreatic cysts, cerebral aneurysms, cardiac valvular anomalies and vascular anomalies may also occur ${ }^{10}$.

Although, ADPKD is a systemic disease, it shows a focal expression because less than $5 \%$ of nephrons become cystic $^{11}$. As the disease is mainly caused by truncating mutations in PKD1 and PKD2 genes, inadequate levels of poly-cystic (haplo insufficiency) may cause ADPKD ${ }^{12}$.

Clinical features of ADPKD usually begin in the $3^{\text {rd }}$ to $4^{\text {th }}$ decade of life but cysts may be detected in the childhood and in utero ${ }^{13}$.

Pain is one of the most common symptoms of ADPKD, occurring in $50 \%$ of affected individuals. Low back pain, abdominal pain, headaches, chest pain and leg pain may be the presenting complaint of ADPKD ${ }^{14}$.

Hematuria occurs in $30-35 \%$ affected patients and usually is self limited lasting for less than one week ${ }^{15}$. Hypertension is present in $10-15 \%$ of children and 60 $70 \%$ of adults before the onset of renal failure in these patients $^{16,17,18}$.

A decrease in urine concentrating ability may be detected in early stage of disease. Micro albuminuria occurs in $35 \%$ of ADPKD patients. Patients usually develop renal failure in fourth to sixth decade of life $e^{1,19}$.

Patients may present with stroke due to associated cerebral aneurysm, or abdominal pain due to aortic aneurysm ${ }^{10}$. Symptoms generally increase with age. Very rarely, children present with renal failure from $A D P K D^{13}$.

Palpable bilateral flanks masses, nodular hepatomegally due to poly-cystic liver disease and signs of renal failure may be the presenting complaints ${ }^{5}$.

Ultrasonography is the most useful imaging technique for the diagnosis of ADPKD. It is also useful for exploring the extra renal cysts in pancreas, liver ${ }^{5,20}$. Diagnostic criteria for ADPKD1 were established by Ravine et al in 1991 and these are ${ }^{21}$.

- $\quad$ At least 2 cysts in 1 kidney or 1 cyst in each kidney in at risk patient younger than 30 years old.

- $\quad$ At least 2 cysts in each kidney in at risk patient aged $30-59$ years.

- $\quad$ At least 4 cysts in each kidney for at risk patient aged 60 or older.

- $\quad$ Presence of hepatic or pancreatic cysts supports diagnosis.

CT scan is more sensitive than USG and can detect cysts of $0.5 \mathrm{~cm}$ in size, but involves radiation and is expensive $^{20}$. Genetic testing is available by means of DNA linkage analysis. It has accuracy rate of more than99\% for ADPKD1 and ADPKD2. This is performed on blood ${ }^{8,9}$.

Treatment of ADPKD is medical as well as surgical. Medical treatment includes ${ }^{22,23}$.

- $\quad$ Non hypertensive ADPKD patient should have USG once a year.

- $\quad$ More frequent visits for hypertensive patients. Patients with renal failure needs more frequent monitoring depending upon the severity of the condition. Medical therapy is necessary to 
accomplish following.

- $\quad$ Control of blood pressure up to 130/85. If urinary protein is more than $18 \mathrm{gm} /$ day, target blood pressure should be less than $125 / 75 \mathrm{~mm} / \mathrm{Hg}$. By achieving good blood pressure control progression of renal disease can be slowed. The drug of choice is ACE inhibitors. It also helps to decrease the progression of renal disease ${ }^{23}$.

- $\quad$ Control abnormalities related to renal failure like hyperkalemia, hyperphosphatemia, hypocalcemia, acidosis, hyperparathyroidism.

- $\quad$ Treat urinary tract infections.

- $\quad$ ADPKD may need renal replacement therapy in the form of haemodialysis, peritoneal dialysis.

Surgical treatments includes decompression of cysts for pain relief, drainage of infected cyst by percutaneous ultrasound guided aspiration ${ }^{22,24}$. Reducing the cyst by sclerosing agent with alcohol and deroofing by laparoscopy is another option ${ }^{22,24}$.

Nephrectomy in ADPKD is indicated for massive cysts $(>40 \mathrm{~cm})$, in a transplant candidate for space required for graft, with recurrent infections or with possible malignancy ${ }^{25}$.

Patients should be advised to sports to avoid trauma to back or abdomen especially in large palpable kidney. Patients should be educated that there is no cure. Interventions and therapies only slow progress. Preimplantation genetic diagnosis can be made for achieving poly-cystic kidney free pregnancy in couples having one partner affected by ADPKD ${ }^{26}$. There is very little research work done in our country on this hereditary disorder.

\section{Objectives}

1. To document various clinical presentation of ADPKD.

2. To assess the family members of patients having poly-cystic kidney disease.

3. To audit our experience of management of complication of this disease.

\section{MATERIAL \& METHODS}

Study was conducted at Department of Urology Allied Hospital Faisalabad from 01 June 2001-Dec. 2004. All patients presented with the symptoms and signs of polycystic kidney and its various complications were included in the study.

Patients presented by other symptoms and incidentally picked up by ultrasonography were also included in the study. Detailed history and clinical examination was performed in each case. Urine $C / E$, urinary proteins, $\mathrm{CBC}$, blood sugar, blood urea \& serum creatinine were performed in all patients for the presence of renal and extra renal cysts. Patients were advised for close monitoring of blood pressure and in case of hypertension, ACE inhibitors (capoten) were advised to keep their blood pressure less than 130/85.

- $\quad$ They were advised to avoid contact sports.

- $\quad$ Patients presented with infected cysts were treated by aspiration and antibiotics according to culture and sensitivity. Nephrectomy was planned in cases of recurrent infections and large cyst $(<40 \mathrm{~m})$.

Patients of ADPKD presented with stones were treated by ESWL, URS \pm DJ stenting. Patients who presented with renal failure were offered renal replacement therapy in the form of haemodialysis and transplant. Patients with hypertension, symptoms of pain were followed up with interval of 15 days. Patients without any symptoms were followed up with the internal of three months.

Blood pressure monitoring, urine examination, urinary protein examinations and ultrasound of kidney ureter bladder was done at each visit. Patients with established renal failure were managed by maintenance dialysis. A.V fistula on radial artery or brachial artery at wrist or outer side of elbow was made for permanent venous access.

\section{RESULTS}

This study was conducted at the Department of Urology Allied Hospital Faisalabad from 01-01-2001 to 31-122004. A total of 19 patients were included in the study. 
Ten (10) patients were male and 09 patients were female, with a ratio of 1.1:0.9 (Fig-1). Age of presentation ranges from 32 years to 65 years with a mean age of 44.5 years (Table-I).

\section{Fig-1. Male to female ration}

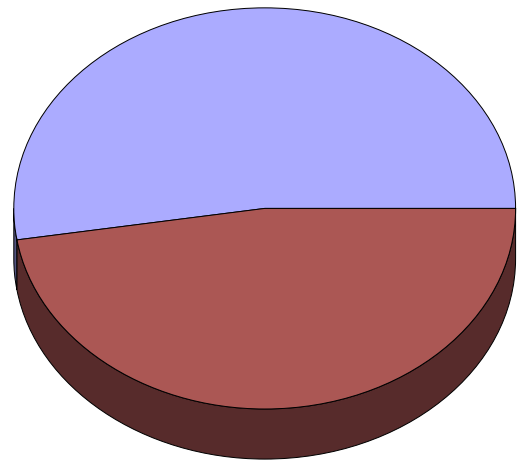

Male

Female

Abdominal pain and flank pain was the presenting complaint in majority $18(95 \%)$ of patients. Fever was present in 10(53\%) patients. Renal stones were present in $08(42 \%)$ cases. Nausea/vomiting and hematuria were present in $13(68 \%)$ and $05(26 \%)$ patients respectively (Fig-2).

\begin{tabular}{|c|c|c|}
\hline \multicolumn{3}{|c|}{ Table-I. Age distribution of patients } \\
\hline Age group & No. of patients & $\%$ Age \\
\hline $30-40$ Yrs & 08 & $42 \%$ \\
\hline $41-50$ Yrs & 07 & $37 \%$ \\
\hline $51-60$ Yrs & 03 & $16 \%$ \\
\hline $61-70$ Yrs & 01 & $05 \%$ \\
\hline
\end{tabular}

Extra renal manifestation of ADPKD was present in 02(11\%) patients, having cysts in liver in addition to polycystic kidneys. 06(32\%) patient had to be given renal replacement therapy in the form of haemodialysis, at different time's of this study. $03(16 \%)$ of these patients died in this period. Renal transplant could not be

performed in any patient. Hypertension was detected in $14(74 \%)$ of patients. These patients were treated with ACE inhibitors and blood pressure was controlled. Rise in renal profiles up to creatinine level of $4.0 \mathrm{mg}$ was detected in $04(21 \%)$ patients. Patients in which urinary tract infection was detected were treated with antibiotic according to culture and sensitivity of urine.

Families of patients were investigated by detailed history, clinical examination, ultrasound KUB and abdomen, urine examination. Father/mother of $04(21 \%)$ patients had PKD. 02(10.5\%) were normal and 03(16\%) died of CVA. In 10(52.6\%) patients, mother/father could not be evaluated due to their death (majority unknown case). $04(21 \%)$ patients had one sister/brother in their family of having ADPKD and 02(10.5\%) had two brother/sisters involved by ADPKD. None of patients had ADPKD in their children detected by USG, KUB and abdomen neither of these had any evidence of its complication.

Retrograde stenting (DJ Stent) had to be performed in two patients to relieve ureteric obstruction followed by ESWL.

Fig-2. Presentation of patients

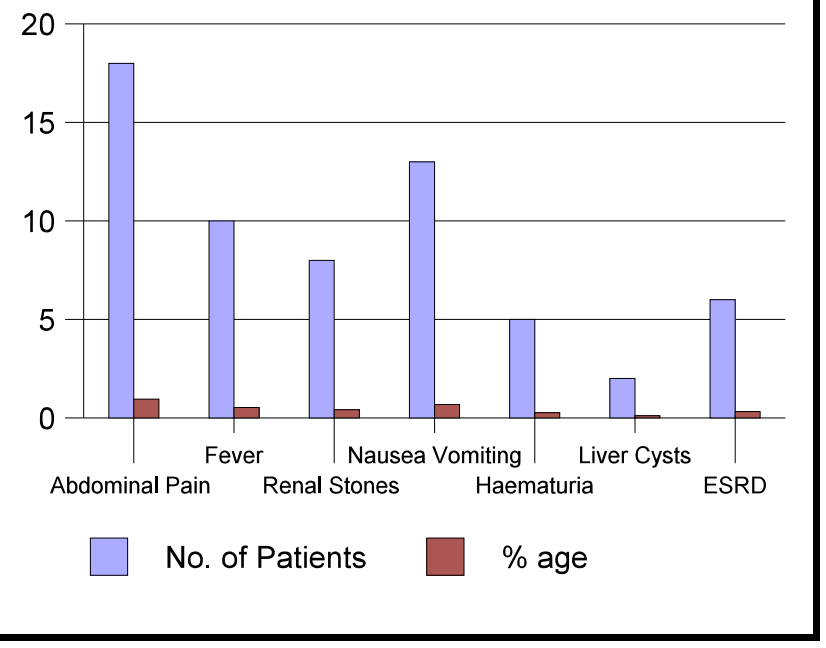

\section{DISCUSSION}

ADPKD is a hereditary disorder. No specific medication is available to treat this disease. Clinical presentation and male to female ratio in this study are similar to other 
series reported in literature ${ }^{14,15}$.

Diagnosis and evaluation of family for ADPKD in this series depended on the presence of bilateral renal cysts in patients and their family members.

In contrary confirmation of diagnosis and early pick up in family members were done in other series by chromosome analysis ${ }^{7}$

Chromosomal analysis is helpful in early diagnosis of ADPKD. Monitoring of these patients can be started at earlier age to delay the onset of complications.

Due to poverty of patients and lack of chromosome analysis facility free of cost was the main cause of missing this important investigation in our series. Due to lack of financial resources, we were unable to perform this essay and due to this reason were unable to detect the patient of ADPKD before any clinical presentation or complications.

Pain was the main presentation by the patient in this series. All the patients were managed by analgesics (NSAIDS and antispasmodics).

Per-cutaneous cyst aspiration, deroofing or nephrectomy was not performed in any case to manage the pain, infection or hematuria.

This was in contrary to other series in which nephrectomy was performed to relieve pain, recurrent infection and hematuria ${ }^{25}$

Culture and sensitivity of urine was performed in patient having urinary tract infections. They were given antibiotics according to culture and sensitivity reports for cure of infection.

Hematuria was present in $05(26 \%)$ patients, which resolved over a period of two weeks. Blood transfusion had to be given only in two patients, one pint of blood each. These findings are comparable to other series reported in the literature ${ }^{15}$.
Hypertension and its control is very important aspect of medical management. With the help of ACE inhibitors all the patients have controlled blood pressure most of the time less than $130 / 90 \mathrm{~mm} \mathrm{Hg}$. Hypertension was managed effectively by ACE inhibitors like other series ${ }^{23}$.

Patients who developed ESRD were offered renal replacement therapy in the form of haemodialysis and renal transplants. All 06 patients were initially dialyzed with temporary venous access through right subclavian vein. Later on permanent venous access was made on left radial artery above wrist joint in all patients.

As a policy of our department, we don't accept non related donors. Only related donors are accepted. 03 patients died during this period. 03 patients with ESRD are on maintenance dialysis. They have been advised renal transplant. But due to non availability of donors we could not perform transplant surgery in these patients as yet.

\section{CONCLUSION}

ADPKD is autosomal dominant hereditary disease having no specific therapy.

Early diagnosis and specific measures like control of blood pressure, infections, hematuria, proteinurea may delay the onset of ESRD.

Patients and their relatives should be explained that there is no cure of this disease.

Counseling should be done to the patients of ADPKD to avoid cousin marriage to decrease the likelihood of passing the disease to next generation with increase frequency.

\section{REFERENCES}

1. York Pei, MD. Molecular genetics of autosomal dominant poly-cystic kidney disease. Clin Invest Med 2003; 26(5): 252-8.

2. Gabow PA. Autosomal dominant poly-cystic kidney disease: N Engl J Med 1993; 329: 332-42. 
3. Harris PC. Autosomal dominant poly-cystic kidney disease: clues to pathogenesis. Hum Mol Genet 1999; 8: 1861-9.

4. Badani KK, Hemal Ak, Menon M. Autosomal dominant poly-cystic kidney disease and pain-A review of the disease from aetiology, evaluation, past surgical treatment options to current practice. J post-grad Med. 2004 Jul-Sep; 50(3): 222-6.

5. Belibi FA, Reif G, Wallace DP, Yamaguchi T, Olsen L, LI $\mathrm{H}$, Helmkamp GM Jr, Grantham JJ. Cyclic AMP promotes growth and secretion in human poly-cystic kidney epithelial cells. Kidney Int. 2004 Sep; 66(3): 96473.

6. Everson GT, Taylor MR, Doctor RB. Poly-cystic disease of the liver. Hepatology. 2004 Oct; 40(4): 774-82.

7. Lee JE, Park MH, Park JH. The gene expression profile of cyst epithelial cells in autosomal dominant polycystic kidney disease patients. J Biochem Mol Biol. 2004 Sep30; 37(5): 612-7.

8. Cox SM, Starzomski RC. Genes and geneticization? The social construction of autosoma dominant polycystic kidney disease. New Genet Soc. 2004 Aug; 23(2): 137-66.

9. Zhang WL, Zhang DY, Wu YM, Sun TM, Mei CL. Gene diagnosis of autosomal dominant poly-cystic kidney disease type 2 using micro satellite DNA tightly linked to poly-cystic kidney disease gene2. Zhonghua Yi Xue Yi Chuan Xue Za Zhi. 2004 Aug; 21(4): 325-8.

10. Weyde W, Krajewska M, Penar J, Bartosik H, Klinger M. Vascular abnormalities in patients with autosomal dominant poly-cystic kidney disease the influence on arteriovenous fistul creation. Clin Nephrol. 2004 May; 61(5): 344-6.

11. Cowley BD Jr. Recent advances in understanding the pathogenesis of poly-cystic kidney disease: therapeutic implications. Drugs. 2004; 64(12): 1285-94.

12. Martin J, Han C, Gordon LA et al. The sequence and analysis of duplication-rich human chromosome 16. Nature. 2004 Dec23; 432(7020): 988-94.

13. Burn M, Maugey-Laulom B, Eurin D, Didier F, Anvi EF Prenatal sonographic patterns in autosomal dominant poly-cystic kidney disease: A multi center study. Ultrasound Obstet Gynecol. 2004 Jul; 24(1): 55-61.
14. Bajwa Zh, Sial KA, Malik AB, Steiman TI. Pain patterns in patients with poly-cystic kidney disease. Kidney Int 2004 Oct; 66(4): 1561-9.

15. Lee DI, Clayman RV. Hand-assisted laparoscopic nephrectomy in autosomal dominant poly-cystic kidney disease. J Endourol. 2004 May; 18(4): 379-82.

16. Ecder T, Schrier RW. Hypertension and left ventricular hypertrophy in autosomal dominant poly-cystic kidney disease. Expert Rev Cardiovasc Ther. 2004 May; 2(3): 369-74.

17. Seeman $T$, Dusek J, Vondrak $K$ et al. Renal concentrating capacity is linked to blood pressure in children with autosomal dominant poly-cystic kidney disease: Physiol Res. 2004; 53(6): 629-34.

18. Loghman-Adham M, Soto CE, Inagami T, Cassis L. The intra-renal renin-angiotensin system in autosomal dominant poly-cystic kidney disease. Am J Physiol Renal Physiol. 2004 Oct; 287(4): F775-88.

19. Igrashi P, Somlo S. Genetics and pathogenesis of polycystic kidney disease. J Am Soc Nephrol 2002; 13: 2384-98.

20. Israel GM, Hindman N, Bosniak MA. Evaluation of cystic renal masses: comparison of CT and MR imaging by using the Bosniak classification system. Radiology. 2004 May; 231(2): 365-71.

21. Ravine D, Gibson RN, Walker RG, et al: Evaluation of ultrasonographic diagnostic crite Autosomal dominant poly-cystic kidney disease 1. Lancet 1994 Apr2; 343(8901):824-7.

22. Torres VE. Therapies to slow poly-cystic kidney disease. Nephron Exp Nephrol. 2004; 98(1): e1-7.

23. Jafar Th, Schmid CH, Strandgaard S, et al. The effect of angiotensin-converting-enzyme inhibitors on progression of advanced poly-cystic kidney disease. Kidney Int. 2005Jan; 67(1): 265-71.

24. Wilson PD: Poly-cystic kidney disease. N Engl J Med 2004 Jan8; 350(2): 151-71.

25. Lopez-Corona E, Garcia-Gonzalez VM, Gablondo F. Results of nephrectomy in patients with Autosomal dominant poly-cystic kidney disease. Rev Invest Clin. 2004 Jul-Aug; 56(4): 437-42.

26. Verlinsky Y, Rechitsky S, Verinsky O, Ozen S, Beck R Kuliev A. Pre-implantation genetic diagnosis for polycystic kidney disease. Fertil Steril. 2004 Oct; 82(4): 9629. 